\title{
Differential effect of steady-state hyperinsulinaemia and hyperglycaemia on hepatic glycogenolysis and glycolysis in rats
}

\author{
S. Halimi, F. Assimacopoulos-Jeannet, J. Terrettaz and B. Jeanrenaud \\ Laboratoires de Recherches Métaboliques, University of Geneva Medical School, Geneva, Switzerland
}

Summary. The action of glucose and of insulin on hepatic glucose production and metabolism has been studied in fed anaesthetized rats during hyperinsulinaemic clamp combined with various steady state levels of glycaemia $(6.8 \pm 0.1$, $9.3 \pm 0.1,11.8 \pm 0.1 \mathrm{mmol} / \mathrm{l})$. Hepatic glucose production was measured using constant infusion of $\mathrm{D}-\left[6-{ }^{3} \mathrm{H}\right]$ glucose. At the end of each clamp the liver was freeze clamped, and enzyme activities and metabolites were measured. Hepatic glucose production was totally suppressed in all the groups receiving insulin. In the group with steady-state normoglycaemia, the suppression of hepatic glucose production was accompanied by a decrease in the levels of glucose-6-phosphate, an increase in those of fructose 2,6-bisphosphate and glycolytic intermediates, but without change in glycogen level or glycogen synthase and phosphorylase. In contrast, in the groups with steady-state hyperglycaemia, phosphorylase $a$ was inactivated, and glycogen synthase activated. Under these conditions, glucose-6-phosphate levels were also decreased and those of fructose 2,6-bisphosphate and glycolytic intermedi- ates were higher than in the group with steady-state normoglycaemia. A slight drop in the level of cAMP was also observed which may contribute, with hyperglycaemia, to the inactivation of phosphorylase. Incorporation of tritiated water into liver glycogen paralleled the activation of glycogen synthase and the accumulation of glycogen. The data indicate that, at normoglycaemia, insulin may suppress hepatic glucose production by channeling glucose-6-phosphate into the glycolytic pathway; at higher levels of glycaemia, a decreased rate of glycogenolysis and an increased rate of glycogen synthesis due to phosphorylase $a$ inactivation and synthase activation may contribute to the decreased level of glucose-6-phosphate, and to a sparing and a net synthesis of glycogen.

Key words: Glucose effects, insulin effects, glycogen synthesis, glycogen degradation, glycolytic intermediates, hepatic glucose production.
The respective mechanisms of the action of glucose and of insulin on hepatic carbohydrate metabolism are still unsettled in normal rodents due to the lack of action of insulin per se in vitro. However, a number of in vivo studies have investigated the rapid effect of the hormone on hepatic glucose production [1-4]. In a recent paper [1] we have presented evidence that, in the fed rat and after a euglycaemic hyperinsulinaemic clamp, the suppression of hepatic glucose production could be correlated with a lower level of glucose6-phosphate (G6P), probably due to an increase in the rate of glycolysis or to a decreased gluconeogenesis, while the respective activities of glycogen phosphorylase and synthase were unchanged. As this study was performed only at euglycaemia, the present work investigates the effect of glucose per se on the relationships between hepatic glucose production, G6P levels and the rate of glycolysis at various steady state levels of glycaemia in fed anaesthetized rats. An infusion of labelled glucose was established to measure hepatic glucose production. At the end of each "clamp", the liver was removed, and glycogen synthesizing and degrading enzyme activities were measured together with various glycolytic intermediates, glycogen and cAMP levels.

\section{Materials and methods}

Ten- to 12-week-old lean male (FA/FA) rats bred in our laboratories and originally purchased from the Centre de Sélection et d'Elevage d'Animaux de Laboratoire (Centre National de la Recherche Scientifique, Orléans, France) were used. The animals were fed ad libitum with a standard laboratory chow and studied between 10.00 and 13.00 hours, i.e. $3-4 \mathrm{~h}$ after food removal.

\section{Clamps at varying steady states of glycaemia}

The clamps were performed in anaesthetized animals (Nembutal intraperitoneally $50 \mathrm{mg} / \mathrm{kg}$ ) as described previously [2]. Two catheters were inserted in the right jugular vein, one for glucose and insulin 
and the other for D- $\left[6-{ }^{3} \mathrm{H}\right]$ glucose infusion and one in the right carotid artery for blood sampling. A total of $1.2 \mathrm{ml}$ of blood was withdrawn during the experiment (hematocrit was $51 \pm 0.5$ and $48 \pm 0.9 \%$ at the beginning and at the end of the clamp respectively). A tracheotomy and a laparotomy were then performed and the abdomen rapidly closed with a loose suture. This procedure allowed for a rapid sampling of the liver at the end of the clamps and minimized the stress of laparotomy prior to the biopsy. At the end of the experiment the abdominal suture was removed and the main lobe of the liver immediately frozen in Wollenberg clamps. Body temperature was maintained between 36.5 and $37.5^{\circ} \mathrm{C}$ using a heating blanket with a rectal probe.

After surgery, the infusion of $\mathrm{D}-\left[6_{-}{ }^{3} \mathrm{H}\right]$ glucose was initiated with a priming dose followed by a continuous infusion of $0.15 \mathrm{uCi} / \mathrm{min}$. This allowed the establishment of a steady state of the specific activity of plasma glucose after $50-60 \mathrm{~min}$ [2]. After $1 \mathrm{~h}, 2$ successive (10 min) samples of blood were taken for basal glycaemia, insulinaemia and ${ }^{3} \mathrm{H}$ glucose. Insulin $(3 \mathrm{mU} / \mathrm{min})$ and unlabelled glucose (1 min later) were then infused, the rate of unlabelled glucose infusion being corrected manually every $5 \mathrm{~min}$ to maintain the desired level of glycaemia. Total glucose appearance $(\mathrm{Ra})$ was calculated by dividing the rate of tracer infusion by the specific activity of plasma glucose at the end of the $60 \mathrm{~min}$ of steady-state glucose level. Hepatic glucose production (HGP) was calculated as follows: $\mathrm{HGP}=\mathrm{Ra}-$ glucose infused. The specific activity of plasma glucose was similar after 50 and $60 \mathrm{~min}$ clamp. Since the glucose infusion was constant, one may conclude that steady state was reached.

All the label remained in glucose, since its specific activity is the same before and after chromatography on an ion exchange column (Dowex AG2-X8, Fluka AG, Buchs, Switzerland).

Incorporation of tritiated water $\left({ }^{3} \mathrm{H}_{2} \mathrm{O}\right)$ into liver glycogen was measured as described in [5]. Tritiated water $(2 \mathrm{mCi})$ was injected after $15 \mathrm{~min}$ of clamp or saline infusion through one of the jugular catheters. No D- $\left[6{ }^{3} \mathrm{H}\right]$ glucose was infused during these experiments, which were otherwise similar to those in which glucose production and utilization were measured.

Specific activity of ${ }^{3} \mathrm{H}_{2} \mathrm{O}$ was measured every $15 \mathrm{~min}$ and found constant. Liver glycogen was isolated [6] and determined as glycosylresidues after amyloglucosidase treatment. Results are expressed as $\mu \mathrm{g}$-atom ${ }^{3} \mathrm{H} / \mathrm{g} / \mathrm{h}$.

\section{Analytical methods}

Blood was collected in heparinized tubes and centrifuged immediately. Plasma glucose was measured using the glucose oxidase method, with a Beckman Glucose Analyzer 2 (Beckman Instruments, Inc., Fullerton, Calif., USA). Plasma insulin concentrations were measured by radioimmunoassay using rat insulin as standard, charcoal-dextran being used to separate free from bound insulin [7].

For the determination of the specific activity of $\mathrm{D}-\left[6-{ }^{3} \mathrm{H}\right]$ glucose, $25 \mu \mathrm{l}$ plasma were deproteinized with $25 \mu \mathrm{ZnSO}_{4}(0.3 \mathrm{~N})$ and $25 \mu \mathrm{l}$ $\mathrm{Ba}(\mathrm{OH})_{2}(0.3 \mathrm{~N}) .25 \mu \mathrm{l}$ of the supernatant were evaporated to dryness at $70^{\circ} \mathrm{C}$ to eliminate tritiated water, redissolved in 1001 water and counted. Glycogen synthase and phosphorylase were assayed at $30^{\circ} \mathrm{C}$ as described by Hue et al. [8] and Stalmans et al. [9]. Metabolite concentrations were determined in a neutralized trichloracetic extract [10] by fluorimetry (Aminco fluoro-colorimeter, American Instrument Company, Silver Spring, Md, USA). A standard curve in the same range of concentration as the hepatic extract was run with each intermediate. Cyclic AMP was assayed in the same extracts [11] after chromatography on Dowex AG $50 \mathrm{~W}$ X4 and lyophilisation.

Fructose 2,6-bisphosphate was measured according to Van Schaftingen [12] in 100-150 $\mathrm{mg}$ frozen liver samples homogenized in $50 \mathrm{mmol} / 1$ sodium hydroxyde. An aliquot was acid degraded and fructose 2,6-bisphosphate re-measured to evaluate the contribution of other activators. This contribution was always minimal (i.e. less than $5 \%$ of the value measured in the alcaline extract). Glycogen was determined as in Hue et al. [13].
Table 1. Definition of the groups

\begin{tabular}{|c|c|}
\hline Group I: & Rats infused with sodium chloride \\
\hline Group II: & $\begin{array}{l}\text { Rats infused with insulin }(3 \mathrm{mU} / \mathrm{min}) \text { and glucose to } \\
\text { maintain a steady state glycaemia of about } 6.5 \mathrm{mmol} / 1\end{array}$ \\
\hline Group III: & $\begin{array}{l}\text { Rats infused with insulin ( } 3 \mathrm{mU} / \mathrm{min}) \text { and glucose to } \\
\text { achieve a steady state glycaemia of } 9 \mathrm{mmol} / 1\end{array}$ \\
\hline Group IV & $\begin{array}{l}\text { Rats infused with insulin }(3 \mathrm{mU} / \mathrm{min}) \text { and glucose to } \\
\text { achieve a steady state glycaemia of } 11 \mathrm{mmol} / 1\end{array}$ \\
\hline
\end{tabular}

Table 2. Hepatic glucose production (HGP) and total glucose utilization (Rd) in fed rats during a saline infusion or during a hyperinsulinaemic clamp with various steady-state levels of glycaemia

\begin{tabular}{llcc}
\hline & $\begin{array}{l}\text { HGP } \\
(\mathrm{mg} / \mathrm{min})\end{array}$ & $\begin{array}{l}\mathrm{Rd} \\
(\mathrm{mg} / \mathrm{min})\end{array}$ \\
\hline Group I & $(n=10)$ & $2.69 \pm 0.14$ & $2.69 \pm 0.14$ \\
Group II & $(n=10)$ & $0.01 \pm 0.30^{\mathrm{a}}$ & $5.34 \pm 0.30^{\mathrm{a}}$ \\
Group III & $(n=6)$ & $-0.22 \pm 0.30^{\mathrm{a}}$ & $7.40 \pm 0.5^{\mathrm{a}}$ \\
Group IV & $(n=6)$ & $-0.52 \pm 0.18^{\mathrm{a}}$ & $10.70 \pm 0.94^{\mathrm{a}}$ \\
\hline
\end{tabular}

Values are mean $\pm S E$ for the number of rats shown in parentheses and expressed per rat. ${ }^{a} p<0.005$ compared to group I

The weight of the rats was comparable in the 4 groups. Group $I=259 \pm 11 ; \quad$ group $I I=267 \pm 5 ; \quad$ group $I I I=240 \pm 2$; group IV $=253 \pm 9 \mathrm{~g}$. Mean glucose infused during the last $30 \mathrm{~min}$ of steady-state glycaemia was $5.37 \pm 0.15, \quad 8.25 \pm 0.61, \quad 10.7 \pm$ $0.72 \mathrm{mg} / \mathrm{min}$ in group II, III and IV respectively

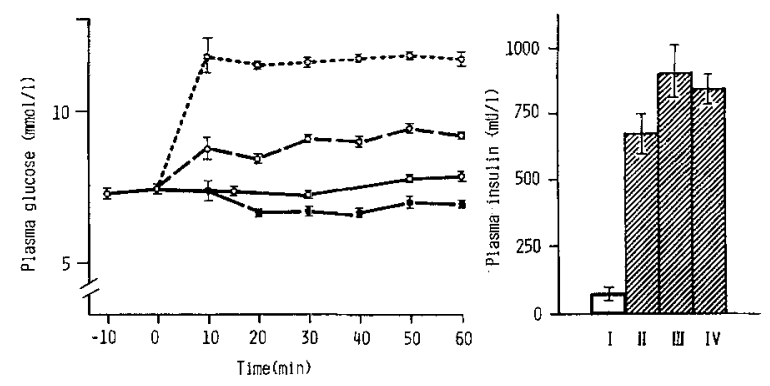

Fig. 1. Glycaemia and insulinaemia in fed rats during saline (group I) or glucose (group II to IV) infusion to obtain various steady-state levels of glycaemia. Group I $\bigcirc-O$, group II $\longrightarrow$, group III $\mathrm{O}_{--} \mathrm{O}$ group IV $\mathrm{O}---\mathrm{O}^{-}$. Open bar: control group; hatched bars: hyperinsulinaemic clamp with various levels of glycaemia. Number of rats in each group as in Table 2

\section{Statistical analysis}

The data are expressed as means \pm SEM for the number of independent experiments. Statistical significance of results was assessed by unpaired Student's t-test.

\section{Results}

\section{Description of the groups}

To study the effect of blood glucose level on hepatic enzyme activities and glycolytic intermediates, a high level of insulinaemia was imposed in all the groups together with various steady state levels of glycaemia. This protocol had to be adopted since, in the rat, so- 
Table 3. Level of metabolites and of cAMP in the liver of fed rats after a saline infusion or after hyperinsulinaemic clamp with various steadystate levels of glycaemia

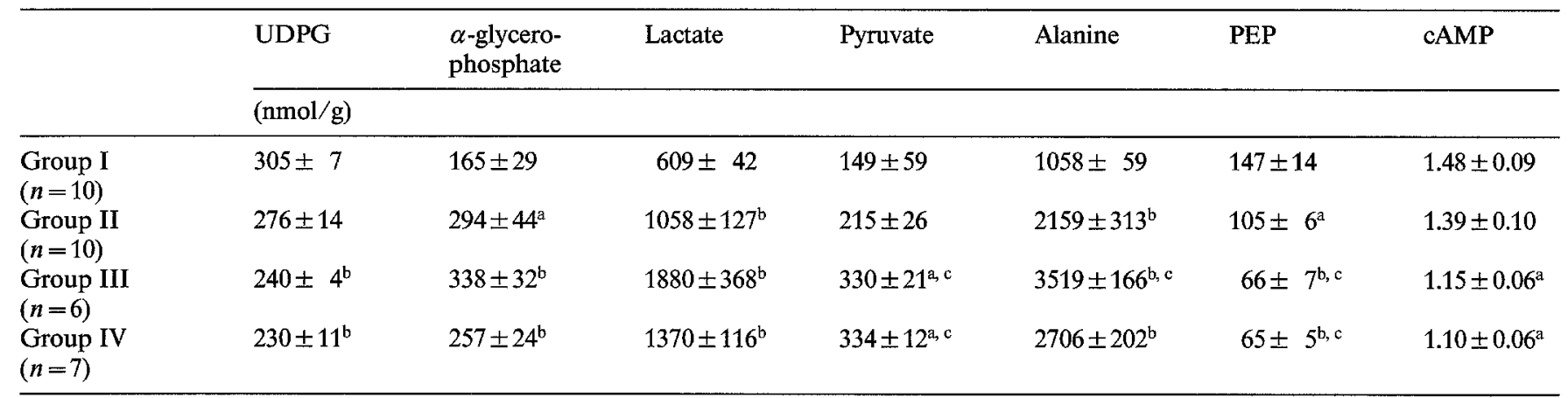

Values are mean $\pm \mathrm{SE}$ for the number of rats shown in parentheses.

${ }^{\mathrm{a}} p<0.05 ;{ }^{\mathrm{b}} p<0.005$ compared to group I, ${ }^{\mathrm{c}} p<0.05$ compared to group II.

Groups are defined in Table 1.

UDPG: uridine diphosphoglucose; PEP: phosphoenolpyruvate

matostatin does not inhibit insulin secretion to a sufficient extent to maintain similar levels of the hormone in eu- and hyperglycaemic states. (J. Terrettaz, unpublished observation). Table 1 defines the 4 groups studied. One group (group I) was infused with the tracer $\mathrm{D}-\left[6^{-}{ }^{3} \mathrm{H}\right]$ glucose together with saline and is referred to as control group; the three other groups were clamped at varying levels of glycaemia, namely $6.8 \pm 0.1 \mathrm{mmol} / 1$ (group II), $9.3 \pm 0.1 \mathrm{mmol} / 1$ (group III) and $11.8 \pm$ $0.1 \mathrm{mmol} / 1$ (group IV), in the presence of high and comparable levels of insulin (Fig.1). Hyperinsulinaemia suppressed totally hepatic glucose production (HGP) (Table 2). Therefore, no additive effects of hyperglycaemia on HGP could be observed. Although in hyperglycaemic state the liver may take up glucose [14], the tracer technique does not allow the measurement of hepatic glucose uptake which is included in total glucose disappearance $\left(R_{d}\right)$.

\section{Effects of hyperinsulinaemia and of hyperglycaemia on the level of metabolites and on glycogen synthesis}

Hyperinsulinaemia in the presence of $6.8 \mathrm{mmol} / 1$ glucose promotes an increase in the levels of fructose 2,6-bisphosphate, the potent stimulator of hepatic 6-phosphofructo-kinase (Fig. 2). Hyperinsulinaemia also brings about an increase in the levels of several glycolytic metabolites, i.e. $\alpha$-glycerophosphate, lactate, pyruvate, alanine. These changes suggest an increased flux through glycolysis and/or a decreased flux through gluconeogenesis. Possibly as a consequence of the increased rate of glycolysis, G6P level decreases (Fig. 2). Hyperglycaemia (groups III and IV) levels resulted in further increases in the levels of fructose 2,6-bisphosphate as well as those of glycolytic intermediates, while keeping G6P at a low concentration compared to the control group I (Fig.2, Table 3). In these groups (III, IV), a significant decrease $(p<0.005)$ in the activity of glycogen phosphorylase and in the level of uridine diphosphoglucose (UDPG, Table 3) was ob-
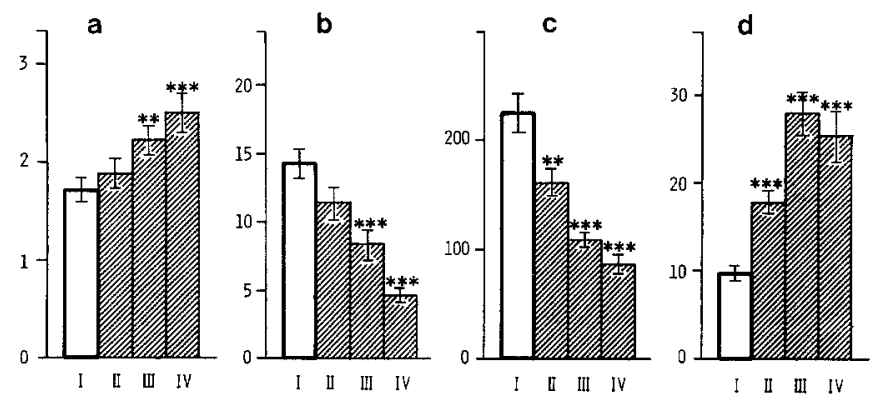

Fig. 2. a Glycogen level (mmol/g), b phosphorylase $a$ activity $(\mathrm{U} / \mathrm{g})$, c glucose-6-phosphate level (nmol/g), d fructose 2,6-bisphosphate levels $(\mathrm{nmol} / \mathrm{g}$ ) in livers from fed rats after saline (group I) or glucose (groups II to IV) infusion to obtain various steady-state levels of glycaemia. Number of rats in each group as in Table $2 .{ }^{* *} p<0.05$ compared to group I. ${ }^{* * *} p<0.005$ compared to group I

served, together with a higher level of glycogen (Fig. 2). This increase in glycogen could result from a decreased degradation suggested by the lower phosphorylase activity with or without an increased synthesis. To test this hypothesis, clamps similar to those of groups I, II, III, IV were performed in which ${ }^{3} \mathrm{H}_{2} \mathrm{O}$ incorporation into glycogen was measured. These experiments were performed in two series and are presented on Table 4. In order to minimize inter-animal differences in glycogen levels, the clamps were performed at exactly the same time of the day (i.e. at 14.00 hours, food being withdrawn at 8.00 hours). In group II, no differences were observed in the parameters measured (Table 4). In groups III and IV, hyperglycaemia produced an inhibition of phosphorylase (Fig. 2, Table 4), an activation of synthase and an increase in ${ }^{3} \mathrm{H}_{2} \mathrm{O}$ incorporation into glycogen, resulting in an increased level of the latter.

\section{Effect of hyperglycaemia on the level of cAMP}

The level of glucagon is known to decrease with hyperglycaemia [15]. This may modify the level of cAMP 
Table 4. Tritiated water $\left({ }^{3} \mathrm{H}_{2} \mathrm{O}\right)$ incorporation into liver glycogen, phosphorylase $a$ and synthase $a$ activities in livers of fed rats after a saline infusion or after a hyperglycaemic clamp with various steady-state levels of glycaemia

\begin{tabular}{cllllrr}
\hline & & & $\begin{array}{l}{ }^{3} \mathrm{H}_{2} \mathrm{O} \text { incorporation } \\
\text { into glycogen } \\
\mu \mathrm{g} \text {-atoms }{ }^{3} \mathrm{H} / \mathrm{h} / \mathrm{g}\end{array}$ & $\begin{array}{l}\text { Glycogen } \\
\text { mmol/g }\end{array}$ & $\begin{array}{l}\text { Synthase } a \\
\mathrm{mU} / \mathrm{g}\end{array}$ & $\begin{array}{l}\text { Posphorylase } a \\
\mathrm{U} / \mathrm{g}\end{array}$ \\
\hline $\mathrm{A}$ & Group I & $(n=4)$ & $24.1 \pm 3.0$ & $2.08 \pm 0.09$ & $55 \pm 5$ & $11.0 \pm 1.4$ \\
& Group II & $(n=3)$ & $21.8 \pm 3.2$ & $2.12 \pm 0.23$ & $46 \pm 7$ & $8.1 \pm 1.2$ \\
B & Group I & $(n=5)$ & $33.7 \pm 4.0$ & $1.48 \pm 0.09$ & $138 \pm 25$ & $11.8 \pm 1.2$ \\
& Group III & $(n=4)$ & $71.3 \pm 5.6^{\mathrm{b}}$ & $1.88 \pm 0.14^{\mathrm{a}}$ & $417 \pm 40^{\mathrm{b}}$ & $5.4 \pm 1.2^{\mathrm{b}}$ \\
& Group IV & $(n=4)$ & $70.0 \pm 8.1^{\mathrm{b}}$ & $2.00 \pm 0.10^{\mathrm{b}}$ & $418 \pm 44^{\mathrm{b}}$ & $3.5 \pm 1.1^{\mathrm{b}}$ \\
\hline
\end{tabular}

Values are mean $\pm \mathrm{SE}$ for the number of rats shown in parentheses.

${ }^{\mathrm{a}} p<0.05 ;{ }^{\mathrm{b}} p<0.01$ compared to control group

and thereby the state of phosphorylation of several key enzymes. When cAMP was measured after $60 \mathrm{~min}$ of hyperinsulinaemia with $6.8 \mathrm{mmol} / 1$ of glucose, no modification was measured (Table 3). However, when glycaemia was increased, a slight but significant decrease in the level of cAMP was observed (Table 3 ).

\section{Discussion}

The present study confirms and extends the previous observation [1] that a decrease in glucose-6-phosphate (G6P) may play a key role in the suppression of hepatic glucose production mediated by insulin and/or glucose. In the presence of hyperinsulinaemia and various steady-state levels of glycaemia, the observed inhibition of hepatic glucose production is always associated with a significant decrease in the concentration of hepatic glucose-6-phosphate (Fig. 2). At normal glucose level but high insulinaemia (euglycaemic hyperinsulinaemic clamps, group II), the observed decrease in G6P cannot be attributed to a decrease in glycogen breakdown since phosphorylase $a$ activity is not significantly modified and no sparing or synthesis of glycogen is measured (Table 4). Under these conditions the lower level of G6P is probably the consequence of an increased glycolysis, as strongly suggested by the higher levels of fructose 2,6-bisphosphate and of glycolytic intermediates such as $\alpha$-glycerophosphate, lactate, pyruvate and alanine and by a decrease in phosphoenol pyruvate (Table 3 ). The accumulation of these intermediates may also reflect a suppression of gluconeogenesis by insulin. A possible increased flux through the pentose phosphate pathway is not excluded, but was not investigated in the present study. When glycaemia is increased (hyperglycaemic hyperinsulinaemic clamps, groups III and IV), similar but more marked increases in fructose 2,6-bisphosphate as well as in glycolytic intermediates were measured. The large increase in fructose 2,6-bisphosphate, in spite of a lower level of G6P, could result from an effect of insulin on 6-phosphofructo-2-kinase and/or on fructose-2,6-bisphosphatase. Phosphorylase activity is now decreased by hyperglycaemia, and glycogen synthase $a$ activity, as well as the incorporation of ${ }^{3} \mathrm{H}_{2} \mathrm{O}$ into glycogen, is increased (Table 4). These changes in glycogen metabolism (decreased glycogen degradation and increased glycogen synthesis) induced by hyperglycaemia and observed in the present study may be explained by two different mechanisms. Firstly, the interaction of glucose with phosphorylase $a$ is known to produce an inhibition of its activity $[16,17]$ as the enzyme becomes a better substrate for phosphorylase phosphatase $[18,19]$. Such an effect of glucose may explain the decreased phosphorylase $a$ activity measured in this study. In addition, an inactivation of phosphorylase $a$ by glucose is known, at a certain threshold value, to deinhibit glycogen synthase phosphatase, thus allowing the activation of glycogen synthase [18]. Secondly, the small but significant decrease in the level of hepatic cAMP observed in the presence of hyperglycaemia in the present study may contribute to the inactivation of phosphorylase $a$ and to the activation of glycogen synthase $a$ via a decrease in cAMP-dependent protein kinase activity.

In livers of rats with high glycaemia (groups III and IV) a higher level of glycogen was measured, compared with those with lower glycaemia (group II), although the concentration of UDPG was decreased by hyperglycaemia (Table 3 ). This suggests that, in this situation, the increased synthesis of glycogen may occur through the activation of glycogen synthase. Such a pull mechanism has been found in fasted rats $1 \mathrm{~h}$ after glucose administration [20]. However, the finding that the effect of hyperglycaemia on glycogen synthase is proportionally greater than its effect on glycogen synthesis may indicate that an increase in substrate level is also necessary for optimal glycogen synthesis.

A complete interpretation of the present data is limited by the absence of measurement of flux through the glycolytic pathway and of glucose uptake by the liver (the tracer technique measuring only glucose production). Measurement of hepatic glucose uptake would require the presence of a catheter in the portal and hepatic vein. Although the former technique has been described [21], there are still technical problems to solve for the latter. The decreased level of G6P measured in all the hyperinsulinaemic groups suggests that 
the phosphorylation of glucose may be a rate limiting step in its metabolism in the liver, as shown by others [22].

The present data suggest the following conclusions. Firstly, at a normal level of steady-state glycaemia insulin suppresses hepatic glucose production, probably by stimulating glycolysis, as evidenced by a drop in the concentration of glucose-6-phosphate together with increases in the concentrations of other glycolytic intermediates and of fructose 2,6-bisphosphate. This effect has previously been suggested to be related to an increase in the activity of pyruvate kinase and possibly in that of the 6-phosphofructo-2-kinase [1]. Secondly, at higher levels of steady-state glycaemia hepatic glucose production continues to be shut off and the glycolytic pathway may be further stimulated, since there are further increases in the concentrations of glycolytic intermediates and fructose 2,6-bisphosphate with the maintenance of low glucose-6-phosphate levels. Furthermore, sustained hyperglycaemia brought additional changes compared to hyperinsulinaemia alone, namely a decreased rate of glycogen degradation and an increased glycogen synthesis. These observed changes in hepatic glycogen metabolism (inactivation of glycogen phosphorylase $a$ and activation of glycogen synthase a) may be explained mainly by two different mechanisms: (1) a direct interaction of glucose with the enzymes of the glycogen metabolism, and (2) a small decrease in hepatic cAMP levels that may be related to a glucose-induced decrease in the level of circulating glucagon.

Acknowledgments. The technical help of Ms. F.Monsch and Ms. $R$. Faes is gratefully acknowledged, as is the secretarial assistance of Ms. C.Deferne. This work has been supported by grant No 3.822.086 from the Swiss National Science Foundation (Berne, Switzerland) and by a grant-in-aid from Nestlé S.A. (Vevey, Switzerland). During this investigation, S.Halimi was supported by the "Fondation pour la Recherche Médicale", France.

\section{References}

1. Terrettaz J, Assimacopoulos-Jeannet F, Jeanrenaud B (1986) Inhibition of hepatic glucose production by insulin in vivo in the rat: contribution of glycolysis. Am J Physiol E346-E351

2. Terrettaz J, Jeanrenaud B (1983) In vivo hepatic and peripheral insulin resistance in genetically obese $(f a / f a)$ rats. Endocrinology 112: 1346-1351

3. Burnol A-F, Leturque A, Ferré P, Girard J (1983) A method for quantifying insulin sensitivity in vivo in the anesthetized rat: the euglycaemic insulin clamp technique coupled with isotopic measurement of glucose turnover. Reprod Nutr Dev 23: 429-435

4. Kraegen EW, James DW, Bennett SP, Chisholm JD (1983) In vivo insulin sensitivity in the rat determined by euglycemic clamp. Am J Physiol 245: E1-E7

5. Postle AD, Bloxham DP (1980) The use of tritiated water to measure absolute rates of hepatic glycogen synthesis. Biochem J 192: $65-73$
6. Chan TM, Exton JH (1976) A rapid method for the determination of glycogen content and radioactivity in small quantities of tissue or isolated hepatocytes. Anal Biochem 71: 96-105

7. Herbert V, Lau KS, Gottlieb CW, Bleicher GSJ (1965) Coated charcoal immunoassay of insulin. J Clin Endocrinol Metab 25: 1375-1384

8. Hue L, Bontemps F, Hers HG (1975) The effect of glucose and of potassium ions on the interconversion of the two forms of glycogen phosphorylase and of glycogen synthase in isolated rat liver preparations. Biochem $\mathbf{J} 152$ : 105-114

9. Stalmans W, Hers HG (1975) The stimulation of liver phosphorylase $b$ by AMP, fluoride and sulfate. A technical note on the specific determination of the $a$ and $b$ forms of liver glycogen phosphorylase. Eur J Biochem 54: 341-350

10. Bergmeyer HU (1974) Methoden der Enzymatischen Analyse. Bergmeyer $\mathrm{HU}$ (ed). Verlag Chemie, Weinheim

11. Gilman AG (1970) A protein binding assay for adenosine $3^{\prime}-5^{\prime}$ cyclic monophosphate. Proc Natl Acad Sci USA 67: 305-312

12. van Schaftingen E, Lederer B, Bartron R, Hers HG (1982) A kinetic study of pyrophosphate: fructose-6-phosphate phosphotransferase from potato tubers. Application to a microassay of fructose 2,6-bisphosphate. Eur J Biochem 129: 191-195

13. Hue L, Bontemps F, Hers HG (1975) The effect of glucose and of potassium ions on the interconversion of the two forms of glycogen phosphorylase and of glycogen synthetase in isolated rat liver preparations. Biochem J 152: 105-114

14. Cherrington AD, Williams PE, Abou Mourad N, Lacy WW, Steiner KE, Liljenquist JE (1982) Insulin as a mediator of hepatic glucose uptake in the conscious dog. Am J Physiol 242: E97-E101

15. Gerich J, Charles M, Grodsky G (1974) Characterization of the effects of arginine and glucose on glucagon and insulin release from the perfused rat pancreas. J Clin Invest 54: 833-841

16. Maddaiah VT, Madsen NB (1966) Kinetics of purified liver phosphorylase. J Biol Chem 241: 3873-3881

17. Stalmans W, De Wulf H, Hue L, Hers HG (1974) The sequential inactivation of glycogen phosphorylase and activation of glycogen synthetase in liver after the administration of glucose to mice and rats. Eur J Biochem 41: 127-134

18. Stalmans W, De Wulf H, Lederer B, Hers HG (1970) The effect of glucose and of a treatment by glucocorticoids on the inactivation in vitro of liver glycogen phosphorylase. Eur J Biochem 15: 9-12

19. Hers HG (1981) Non-hormonal control of glycogen synthesis. In: Hue L, van de Werve $G$ (eds). Short term regulation of liver metabolism. Elsevier, pp 105-117

20. Newgard CB, Foster DW, McGarry JD (1984) Evidence for suppression of hepatic glucose-6-phosphatase with carbohydrate feeding. Diabetes 33: 192-195

21. Helman A, Castaing D, Morin J, Pfister-Lemaire N, Assan R (1984) A new technique for hepatic portal vein catheterization in freely moving rats. Am J Physiol 246: E544-E547

22. Kuwajima M, Newgard CB, Foster DW, McGarry JD (1986) The glucose-phosphorylating capacity of the liver as measured by three independent assays. J Biol Chem 261: 8849-8853

Received: 3 December 1986

and in revised form: 3 March 1987

Dr. S. Halimi

Service Endocrinologie - Diabète

Hôpital des Sablons de Grenoble

F-38043 Grenoble Cedex

France 